\title{
Vocabulary Acquisition in a Foreign Language: Digital Technologies and Learning
}

\author{
Larissa T. da Costa ${ }^{1}$, Carolina Morais R. da Silva ${ }^{1}$ \\ ${ }^{1}$ Universidade Federal do Ceará (UFC) - Fortaleza - CE - Brazil \\ larissatcostadalu.ufc.br, carolinadufc.br
}

\begin{abstract}
The advancement of Information and Communication Technologies (ICTs) over the last decades has resulted in the integration of technology into most of our daily tasks, especially in education. Foreign language learners now have access to a plethora of tools available on mobile devices, including audiovisual tools that support their pronunciation enhancement and vocabulary acquisition process. Considering the benefits of using technology in the classroom, this paper demonstrates a video-recording method used in favor of autonomous foreign language learning.
\end{abstract}

\section{Background}

As technology continually evolved over the years, the amount of time spent using technologies increased as well. Additionally, digital devices have become more accessible to wider audiences and it is noticeable that a greater number of people have started consuming these products. As a consequence, different aspects of our everyday lives had to be reevaluated in order to accommodate the new technologies, and education takes part in it, being a fundamental factor for the construction of social relations in the 21 st century.

Queiros, Gomes, and Oliveira [Queiros, Gomes, and Oliveira 2019] state that “(...) technology has been globally implemented in many areas of education, making itself evident and standing out among researchers and teachers". Mobile devices are more practical, and this feature of mobile technologies is advantageous in terms of their usefulness in education, as these devices provide students the opportunity to extend their learning process beyond the classroom. Furthermore, Martinez-Lage and Herren [Martinez-Lage and Herren 1998] uphold that the use of technologies in the classroom endorses autonomous learning and puts students in control of their learning pace as well.

Mobile technologies such as smartphones and tablet computers have a significant amount of features that may be used for educational purposes, including digital cameras that support video recording, internet access, and downloadable applications (apps). According to Chinnery [Chinnery 2006], these features are highly beneficial in learning contexts, given that they allow students not only to practice the foreign language but also to access authentic material.

Among the tools available on mobile devices, audiovisual content has been gaining extreme popularity over the years, mostly due to the success of streaming platforms such as YouTube, which has almost 2 billion users worldwide. Additionally, demographic research has shown that, in Brazil, 5 out of 10 consumers access YouTube on a daily basis, and $30 \%$ of these consumers use the platform to acquire new knowledge [Youtube Insights 2018]. 
Therefore, it is possible to infer that audiovisual content is accessible - most original content on YouTube is available for free - and it is a relevant source of material for language learning. McNulty and Lazarevic [McNulty and Lazarevic 2012] uphold that using video-based methods in the classroom allows students to engage in a process of autonomous learning, given that they will have the opportunity to check and correct their own errors by watching themselves on the screen. Considering that, nowadays, mobile devices are accessible to most people, and that these devices offer most, if not all, features required in a video-recording process, our paper proposes an audiovisual production method in the foreign language classroom that can help assess students' performance.

\section{Methods}

Our work is based on the Grounded Theory (GT), a qualitative method proposed with the purpose of providing a method that allows researchers to formulate new theories [Silva 2019]. One of the most important characteristics of this theory is that, when researchers apply this method, they do not start their research following a predefined scientific theory that is meant to be proven. Instead, the researcher will establish the goals of the study and the methodology, and the theoretical basis will emerge only during the analysis of the collected data. In other words, it is " (...) data [that forms] the foundation of our theory and our analysis of these data generates the concepts we construct" [Charmaz 2014].

Along with the Grounded Theory, the researchers Glaser and Strauss also proposed an analysis method called the Constant Comparative Method (CCM). Using the CCM, researchers constantly analyze, compare, and contrast the collected data in order to create global categories and to explore all the similarities and differences between the data.

For this research, we have 63 volunteers, all of whom are beginner-level students (A1 level) at Casa de Cultura Britânica (CCB), at the Federal University of Ceará. CCB offers English courses (beginner, intermediate, and advanced) for students of age 13 onwards. Prior to the COVID-19 outbreak, students attended classes once or twice a week at the CCB building at UFC - Campus Benfica. However, due to the pandemic, in-person classes were replaced by online meetings via Google Meet. The general objective of this study is to evaluate the effectiveness of the production of audiovisual content as a tool to evaluate students' performance in a foreign language. For such, the teacher of the class assigned a task that required students to record a short video of themselves answering questions that were available in a suggested script provided by the teacher.

Our study is divided into three distinct phases: the first phase encompasses the collection of data; the second phase of the study comprises the analysis of these data, and data coding is the third and final phase of the study. Two instruments were developed in order to collect data. The first instrument consists of two questionnaires; one designed to be applied before students started the videorecording process (henceforth 'Questionnaire 1'), and one designed to be applied after students recorded their videos (henceforth 'Questionnaire 2'). Questionnaire 1 features questions that were mainly related to the familiarity of students with digital technologies and with video-recording, while Questionnaire 2 concerns the students' 
experience with recording a video for the class. The second data collection instrument is the video itself (henceforth 'Instrument 2'). In GT, the analysis of data is constant, and it starts immediately after the researcher starts collecting data. Thus far, we have collected data from Questionnaire 1, which are being currently analyzed, and we are still collecting the data from both Questionnaire 2 and Instrument 2.

\section{Partial Results \& Final Considerations}

Questionnaire 1 compiled a total of nine questions that were related to digital technologies and to video recording. We started the questionnaire by asking volunteers to tell us their age, and we verified that over $50 \%$ of the participants were between 18 and 29 years old. Out of the total number of students taking part in our research, all 63 students informed us that they already used digital technologies, especially for social networking that includes video-sharing features. This number allows us to infer that the task of recording a video will not impose any major difficulties on the students and that they will positively engage in the activity.

Given the context of the COVID-19 outbreak, we noticed that almost all of the participants started using their technological devices for educational purposes, as they began attending online classes. As to video recording, more than $80 \%$ of the participants stated that they had recorded videos before, either using their mobile phones or their computers.

Through the answers provided by Questionnaire 1, we were also able to assess the participants' expectations regarding the task of recording a short video for their final project. We observed that most of the students expressed positive reactions towards the activity and also expressed their desire to create a high-quality video, both in terms of technical quality and content (performance) quality. The participants also answered another open-ended question that concerned their beliefs regarding the benefits of recording a video as a class project. More than $50 \%$ of the participants stated that they believe that the process of producing audiovisual content for educational purposes will allow them to practice their pronunciation and to improve their vocabulary in the foreign language. These initial results allow us to predict that: 1) given their familiarity and affinity with the digital technologies, students will find the task of recording a video simple and enjoyable; 2) taking students' expectations and beliefs regarding the activity, their videos will allow us to collect data that will contribute positively to our research.

The results obtained thus far raise our expectations for the next steps of our research, as the participants are expressing positive attitudes towards our project and their enthusiasm is likely to be reflected in their videos. The next steps in our research consist of collecting data from both Questionnaire 2 and Instrument 2and analyzing these data in search of elements that will allow us to move forward and test our initial hypothesis that the process of producing audiovisual content will help students engage in an autonomous learning process and improve their foreign language performance. The work presented in this short paper was designed and is being carried out with the intent of contributing to the literature and to the current teaching methods as well, especially considering the need for the integration of technologies in the classroom. 


\section{References}

Charmaz, K. (2014). Constructing Grounded Theory (2nd edition). SAGE Publications.

Chinnery, G. M. (2006). Going to the MALL: Mobile-Assisted Language Learning. In Language Learning \& Technology, 10(1), 09-16.

Martinez-Lage, A., Herren, D. (1998). Challenges and Opportunities: Curriculum pressures in the technological present. In: J. Harper, M. Lively \& M. Williams (Eds.), The coming of age of the profession: issues and emerging ideas for the teaching of foreign languages (pp.141-167). Heinle \& Heinle Publishers.

McNulty, A., Lazarevic, B. (2012). Best Practices in Using Video Technology to Promote Second Language Acquisition. Teaching English with Technology, 12(3), 49-61.

Queiros, L. M., Gomes, A. S., \& Oliveira, F. K. (2019, October). Collaborative Strategies for Professional Development of High School Teachers: Groupware Co-Design for Learning Experience Design. Proceedings of the Second Workshop on Advanced Virtual Environments and Education. WAVE2 2019. Poços de Caldas, MG (pp. 09-12). Brazilian Computer Society.

Silva, C. M. R. (2019). Tecnologias Digitais e Lingua Portuguesa: O Uso da Internet Como Ferramenta para Produção Textual na Escola. [Doctoral dissertation, Universidade Federal do Ceará]. Repositório Institucional UFC. http://www.repositorio.ufc.br/handle/riufc/47474

Youtube Insights (2018). YouTube.

https://youtubeinsights.withgoogle.com/introducao. 